\title{
ORIGIN AND EARLY EVOLUTION OF AVES: DINOSAURS, ANCIENT BIRDS, AND MTDNA SEQUENCES
}

SERENO, Paul C., Dept. of Organismal Biology and Anatomy, University of Chicago, 1027 E. 57th St., Chicago IL 60637, U.S.A.

Recently a general cladistic framework for early avian evolution has emerged. Postcranial modifications in the wrist joint and elsewhere firmly establish birds as a diversified subgroup of maniraptoran theropods. And the best known Mesozoic avians--Archaeopteryx and Late Cretaceous Hesperornis and Ichthyornis --have been positioned as successive sister taxa to living birds. Within this framework, however, several basic phylogenetic questions need to be addressed: (1) Which maniraptorans are most closely related to birds? (2) How was the modern avian skeleton built during the first third of avian history, between Archaeopteryx and Late Cretaceous Hesperornis and Ichthyornis? (3) And what are the relationships between the major groups of living birds?

Avian origins. Synapomorphies listed by Ostrom and others to unite birds and other theropods typically apply to all maniraptorans or higher-level theropod clades, leaving unsettled the question of which maniraptorans constitute the immediate outgroups to birds. Deinonychosauria is confirmed as the sister-group to Aves, based principally on synapomorphies of the pectoral and pelvic girdles. In contrast to some previous suggestions, this study supports monophyly of Deinonychosauria (uniting dromaeosaurids and troodontids), with a single origin of the hyperextendable, raptorial digit II of the pes.

Sinornis and the evolution of powered flight and perching. Archaeopteryx lacks the profound modifications of the avian skeleton that characterize Ichthyornis and modern birds. Recent discovery of Lower Cretaceous birds has brought to light important intermediate stages in the transformation of the avian skeleton. Sparrow-sized Sinornis, discovered in Lower Cretaceous lake deposits in China, exhibits features that are associated with sustained powered flight; the laterally directed glenoid and V-shaped ulnare suggest that the wing was capable of tight flexion during flight. Features unrelated to the flight apparatus, in contrast, have not been altered; the skull is toothed, the manal digits are flexible and clawed, and gastralia are present beneath the rib cage.

Higher-level relationships among living birds. The deep branching history of living birds occurred before the end of the Cretaceous and can be reconstructed from anatomical and genetic evidence in living birds. DNA sequences have been obtained from the mitochondrial cytochrome $b$ gene in a variety of living birds. These data are consistent with a basal split between palaeognaths and neognaths and support the basal position of galliforms and anseriforms among neognaths. Piciforms appear to be closely related to passeriforms, and Corvida does not appear to be monophyletic, in contrast to recent DNA-DNA hybridization results. 